\title{
Tuning the thermoelectric properties of $\mathrm{Ca}_{9} \mathrm{Zn}_{4+x} \mathrm{~S} b_{9}$ by controlled doping on the interstitial structure
}

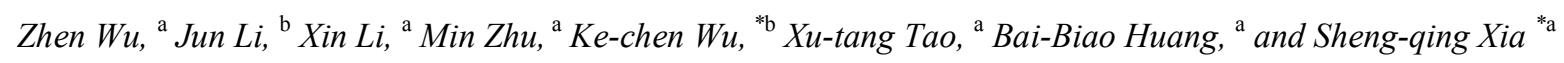

State Key Laboratory of Crystal Materials, Institute of Crystal Materials, Shandong University, Jinan,

Shandong 250100, People's Republic of China

\section{Supporting Information}

\section{Contents}

1. Figure S1. Electronic band structure calculated for the hypothetical ordered model of $\mathrm{Ca}_{9} \mathrm{Zn}_{4.5} \mathrm{Sb}_{9}$. The hole effective mass $\left(m_{p}^{*}\right)$ and electron effective mass $\left(m_{e}^{*}\right)$ for $\mathrm{Ca}_{9} \mathrm{Zn}_{4.5} \mathrm{Sb}_{9}$ are evaluated by fitting the band structures around the valence band maximum and conduction band minimum respectively, using the equation $m^{*}=\hbar^{2} /\left(\mathrm{d}^{2} E / \mathrm{d} k^{2}\right)$.

2. Figure S2. Electronic band structure calculated for the hypothetical ordered model of $\mathrm{Ca}_{9} \mathrm{Zn}_{4} \mathrm{Al}_{0.33} \mathrm{Sb}_{9}$, for which a tripled super cell was constructed with the interstitial site occupied only by Al atoms.

4. Figure S3. Seebeck Pisarenko plot for various doped and undoped materials based on $\mathrm{Ca}_{9} \mathrm{Zn}_{4.5} \mathrm{Sb}_{9}$. Experimental data are shown as scattered dots in different colors and the curves were calculated based on the SPB (Single Parabolic Band) model.

3. Figure S4. Electronic and lattice thermal conductivity of $\mathrm{Ca}_{9} \mathrm{Zn}_{4.5-\mathrm{x}} \mathrm{Al}_{2 \mathrm{x} / 3} \mathrm{Sb}_{9}(\mathrm{x}=0,0.5,1.0)$ extracted by using the Wiedemann-Franz law.

4. Figure S5. Electronic and lattice components of the thermal conductivity for $\mathrm{Ca}_{9} \mathrm{Zn}_{4.5-\mathrm{x}} \mathrm{Cu}_{\mathrm{x}} \mathrm{Sb}_{9}(\mathrm{x}=0$, $0.05,0.1,0.15,0.2)$ extracted by using the Wiedemann-Franz law. 


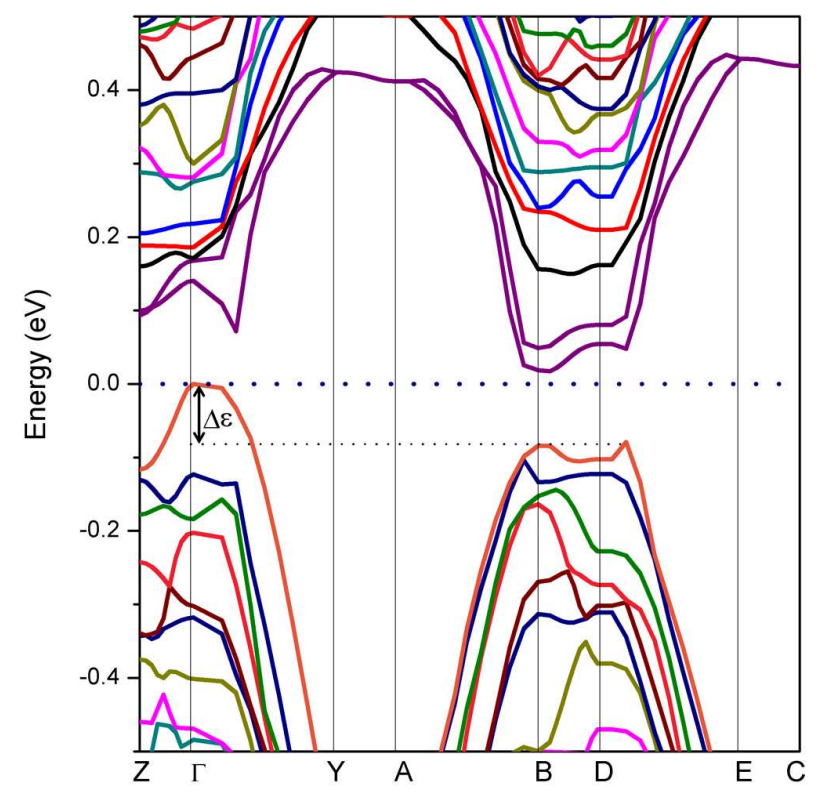

Figure S1. Electronic band structure calculated for the hypothetical ordered model of $\mathrm{Ca}_{9} \mathrm{Zn}_{4.5} \mathrm{Sb}_{9}$. The hole effective mass $\left(m_{p}^{*}\right)$ and electron effective mass $\left(m_{e}^{*}\right)$ for $\mathrm{Ca}_{9} \mathrm{Zn}_{4.5} \mathrm{Sb}_{9}$ are evaluated by fitting the band structures around the valence band maximum and conduction band minimum respectively, using the equation $m^{*}=\hbar^{2} /\left(\mathrm{d}^{2} E / \mathrm{d} k^{2}\right)$. 


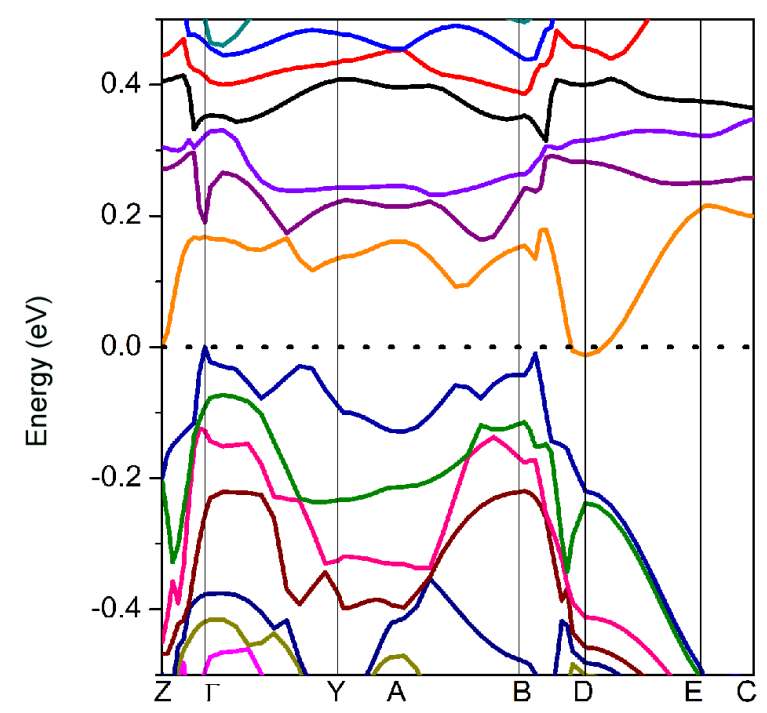

Figure S2. Electronic band structure calculated for the hypothetical ordered model of $\mathrm{Ca}_{9} \mathrm{Zn}_{4} \mathrm{Al}_{0.33} \mathrm{Sb}_{9}$, for which a tripled super cell was constructed with the interstitial site occupied only by Al atoms. 


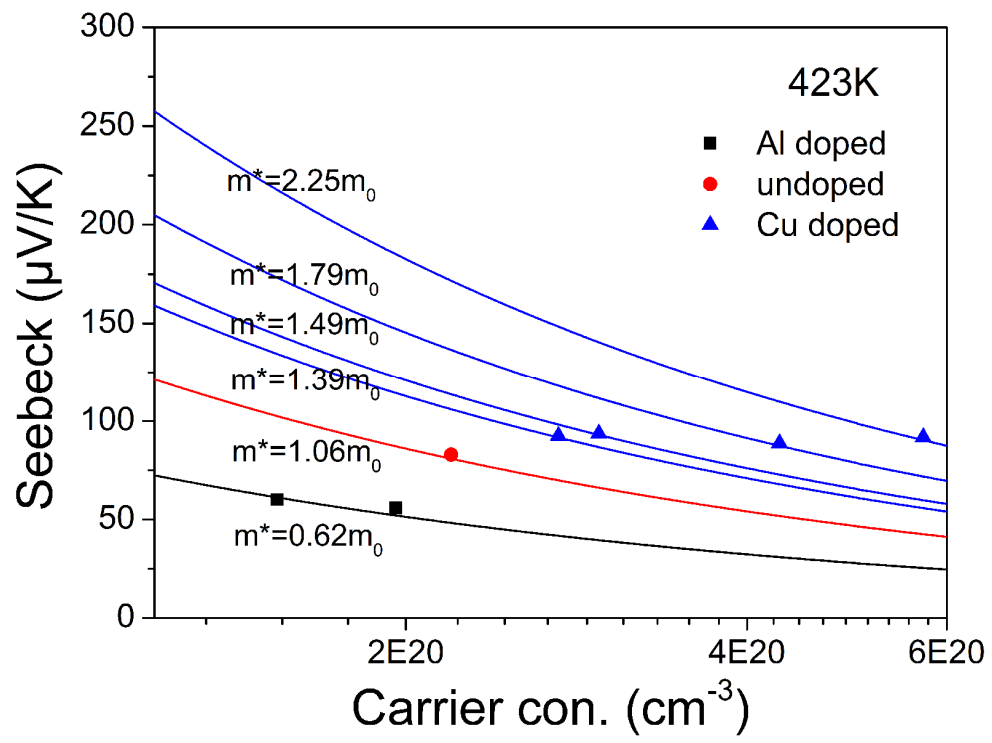

Figure S3. Seebeck Pisarenko plot for various doped and undoped materials based on $\mathrm{Ca}_{9} \mathrm{Zn}_{4.5} \mathrm{Sb}_{9}$. Experimental data are shown as scattered dots in different colors and the curves were calculated based on the SPB (Single Parabolic Band) model. 

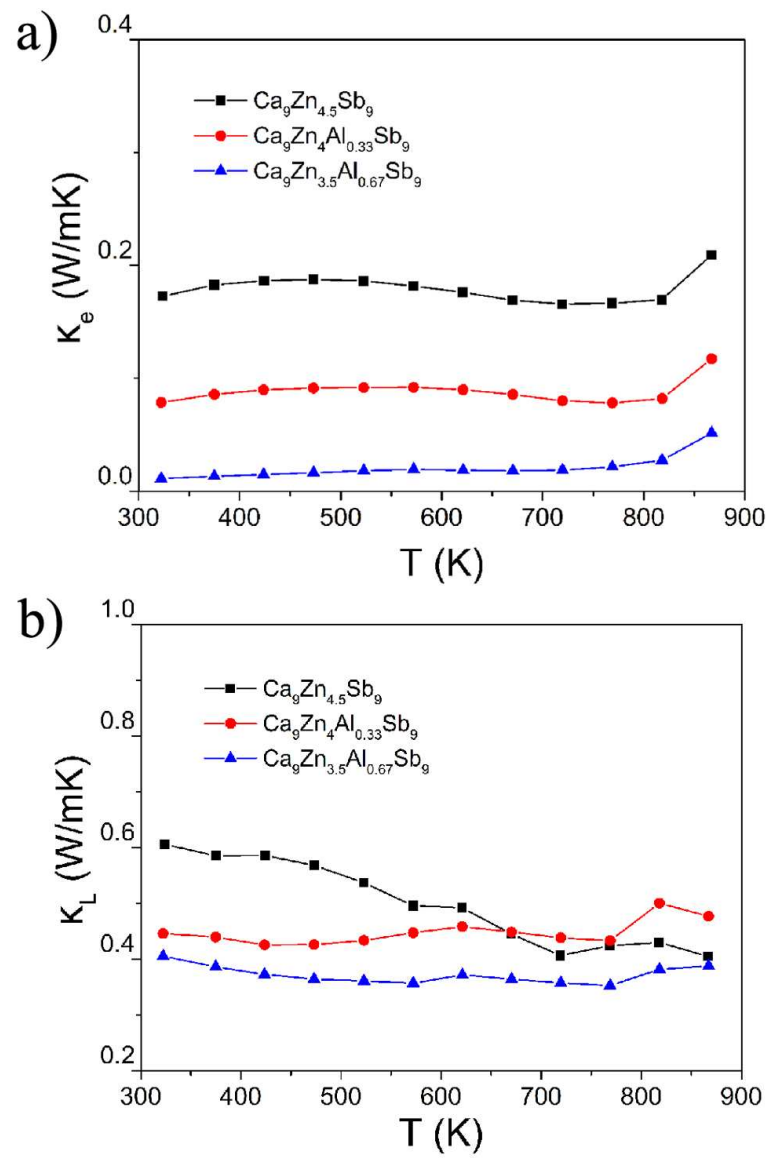

Figure S4. Electronic and lattice thermal conductivity of $\mathrm{Ca}_{9} \mathrm{Zn}_{4.5-\mathrm{x}} \mathrm{Al}_{2 \mathrm{x} / 3} \mathrm{Sb}_{9}(\mathrm{x}=0,0.5,1.0)$ extracted by using the Wiedemann-Franz law. 

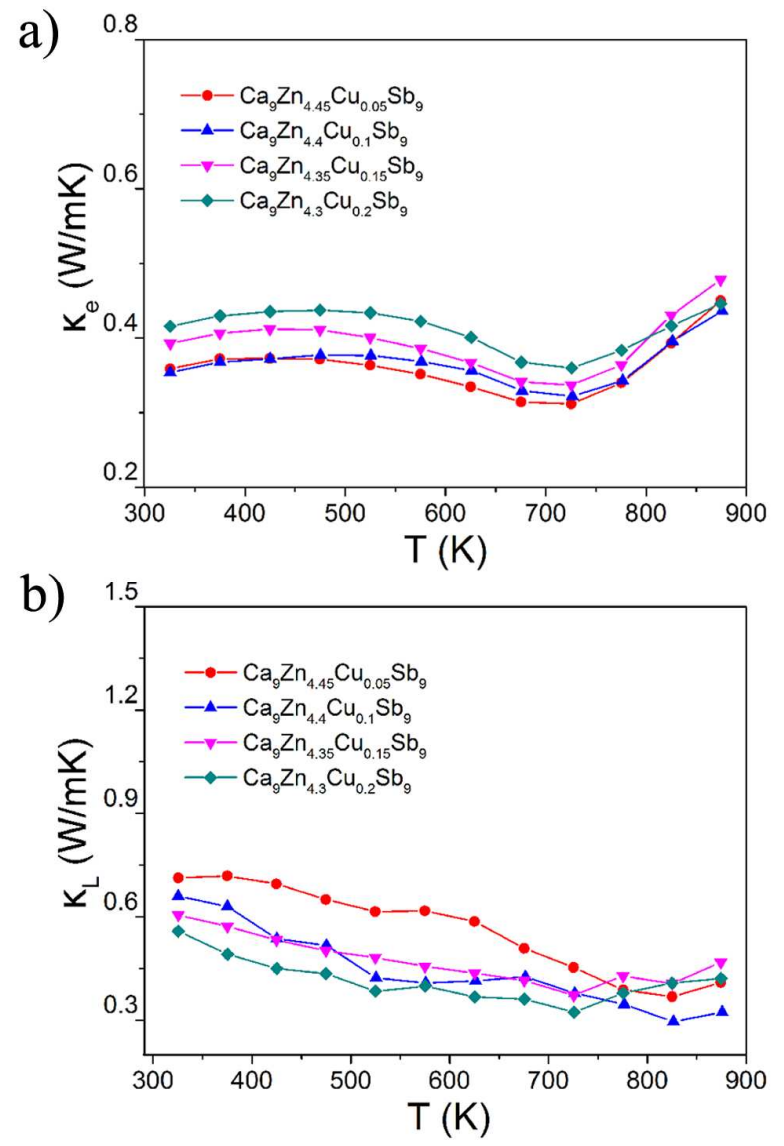

Figure S5. Electronic and lattice components of the thermal conductivity for $\mathrm{Ca}_{9} \mathrm{Zn}_{4.5-\mathrm{x}} \mathrm{Cu}_{\mathrm{x}} \mathrm{Sb}_{9}(\mathrm{x}=0$, $0.05,0.1,0.15,0.2)$. 